\title{
Poesia e transpoética nas performances DA EU LÍRICA DOS POEMAS DE JOY LADIN
}

\author{
Poetry and transpoetics in the performances \\ of the eu lírica in poems by Joy Ladin
}

\author{
Natália Salomé Poubel ${ }^{1}$ \\ Vinícius Carvalho Pereira ${ }^{1}$ \\ ${ }^{1}$ Universidade Federal de Mato Grosso. Cuiabá, MT, Brasil. \\ E-mail: natsalome@gmail.com \\ E-mail: viniciuscarpe@gmail.com
}

\section{RESUMO}

Diante das inúmeras possibilidades de performances de gênero na linguagem, discutimos, neste artigo, a obra da escritora norte-americana Joy Ladin, mulher trans, judia, poetisa premiada e professora universitária, em cuja escrita observamos uma constante reelaboração do performarse mulher, num continuum feminino. Na leitura dos poemas "It Like Me", "The Poem and Me" e "Not Unlike" (LADIN, 2017), atentamos para a ocorrência do que a própria autora chama de trans poética e adotamos diferentes noções da teoria literária feminista e dos estudos de gênero, com destaque para o conceito de eu lírica (POUBEL, 2020). Nessa discussão, entendemos

EDITOR-CHEFE:

Gerson Roberto Neumann

EDITOR EXECUTIVO:

Regina Zilberman

SUBMETIDO: 30.04 .2021

ACEITO: 15.06 .2021

\section{COMO CITAR:}

POUBEL, Natália Salomé; PEREIRA, Vinícius Carvalho.

Poesia e transpoética nas performances da eu lírica dos poemas de Joy Ladin. Revista Brasileira de Literatura Comparada, v. 23 , n. 44 , p. 161-176, set.dez., 2021. doi: https:// doi.org/10.1590/2596304x20212344npvp a escrita como espaço para acolher e expressar identidades que não são estáveis e nem semelhantes, demonstrando como as performances das eu líricas na poesia de Joy Ladin podem moldar variadas mulheres - autoproclamadas mulheres - no discurso e, a partir disso, mudar a direção na qual estas são vistas dentro e fora da linguagem.

PALAVRAS-CHAVE: Joy Ladin; trans poética; eu lírica; performances de gênero; continuum feminino.

\section{ABSTRACT}

Considering the many possibilities of gender performance in language, this paper discusses the work of the American writer Joy Ladin, a Jewish trans woman, awarded poet and professor, whose writing shows a constant reenacting of performing woman, in a feminine continuum. By reading the poems "It Like Me", "The Poem and Me" and "Not Unlike" (LADIN, 2017), we highlight the occurrence of what the author herself called a trans poetics and we adopt different notions from feminine literary theory and gender studies, especially the concept of eu lírica (POUBEL, 2020). In this discussion, we understand writing as a space to welcome and express identities that are neither stable nor similar, showing how the performances of eu líricas in Joy Ladin's poetry can shape various women - self-proclaimed women - in discourse and, based on that, change the way women are seen inside and outside language.

KEYWORDS: Joy Ladin; trans poetics; eu lírica; gender performances; feminine continuum. 
A busca por uma identidade na escrita literária percorre um longo caminho na história da literatura e nas diferentes óticas com as quais se pode estudar literatura. No pós-estruturalismo francês, o descolamento entre texto e autor é pontuado por Barthes (2004) quando este dá vida ao leitor enquanto produtor de significados a partir de sua interação com o texto. Se, por um lado, o autor morre quando nasce o leitor, por outro, quantas vozes podem ser ouvidas a partir do poema que em primeira pessoa ressoa as experiências daquele que deixou o seu rastro ao escrever? Esta discussão percorre diferentes perspectivas, mas aqui a voz lírica não deixará de lado aquela que a transformou em materialidade textual, como também apontará para a polifonia existente no texto enquanto materialidade da linguagem poética.

Para percorrer tal percurso dentro da lírica, o encontro com a poetisa norte-americana Joy Ladin, através de sua obra teórica e poética, foi indispensável para motivar a investigação de como as diferentes vozes femininas - compreendendo aqui voz feminina como aquela que vem de uma pessoa autoidentificada enquanto mulher - aparecem nos poemas e como elas reverberam para além da autora dos textos. Joy Ladin é uma mulher trans norte-americana, judia, poetisa vencedora de prêmios literários como o Lambda Literary Awards e professora da cadeira David e Ruth Gottesman do Stern College for Women da universidade judia ortodoxa Yeshiva, de Nova Iorque. Nascida em março de 1961, foi designada como sendo do sexo masculino ao nascer. Autoidentificando-se como mulher, Ladin anunciou sua transição de gênero em 2007, aos 46 anos de idade. As consequências de sua transição não foram apenas positivas na vida de Joy, pois levaram ao divórcio de sua então esposa, à separação dos filhos e também ao afastamento da Universidade de Yeshiva. A autora apenas conseguiu retornar para a universidade anos mais tarde através de processo judicial.

A autora é também ativista pelos direitos das pessoas trans e atua especialmente dentro das comunidades judias. Dentre suas obras mais famosas estão sua autobiografia intitulada Through the Door of Life: a Jewish Journey Between Genders, de 2012, e o livro de poemas The Book of Anna, de 2007, que foi reeditado com sua republicação em abril de 2021 através de um evento no formato on-line. Em sua obra poética e teórica, é possível observar a convergência entre os temas do judaísmo e da transexualidade, como no livro The Soul of the Stranger: Reading God and Torah from a Transgender Perspective, de 2018.

Neste artigo elucidaremos através de três poemas de Joy Ladin (2017) - "It Like Me", “The Poem and Me" " "Not Unlike" - as possibilidades de leitura de seus textos numa perspectiva da trans poética (LADIN, 2016) e da teoria literária feminista, usando o conceito de eu lírica (POUBEL, 2020) como norteador das análises presentes. Diante das várias possibilidades de performar mulher na linguagem, abre-se com a discussão da eu lírica a enunciação poemática para acolher e também expressar identidades que não são estáveis e nem semelhantes. A intenção é demonstrar, nas análises aqui apresentadas, como as performances das eu líricas na poesia de Joy Ladin podem moldar diferentes mulheres - autoproclamadas mulheres - na instância enunciativa e, a partir disso, mudar a direção na qual estas são vistas para além da enunciação. A eu lírica, como parte da linguagem semiótica (KRISTEVA, 1984), revela na análise dos poemas de Ladin formas transpoéticas de habitar o espaço da linguagem móvel e infinitamente eterna nas possibilidades de ser ou de se tornar mulher. Na teoria literária mais tradicional, encontrada na maioria dos manuais (WELLEK, WARREN, 1971; HAMBURGER, 1975; COUTINHO, 1976; PAZ, 1982; MOISÉS, 2012), frequentemente valemo-nos de conceitos estruturais para analisar poesia. 
Para os estudiosos do campo da literatura, é preciso se apropriar dos termos que norteiam as análises e aplicá-los ao longo das leituras dos poemas e dos textos narrativos. No que concerne à lírica, dentre aspectos de ritmo e sonoridade, de figuras e metro, encontramos também aquele que concerne à voz do poema: quem é que fala no poema? De onde fala? Quem é seu interlocutor?

A instauração de um eu lírico como voz poética, na tradição da crítica e teoria literária, pretende universalizar as demandas que emanam da voz lírica, tornando-a ajustável a todos. Seria o eu lírico que fala no poema, a voz que expressa os sentimentos e pensamentos do texto; seria, pois, essa a figura ficcional e textual que responde pela enunciação do poema. Portanto, independentemente do poeta ou poetisa que tivesse escrito o poema no mundo empírico, o que viria expresso na materialidade do poema não se relacionaria diretamente a uma figura do mundo real, mas sim a essa entidade textualizada como parte do processo enunciativo, numa espécie de entidade poemática. Esse expediente universalizante - de uma voz apenas ficcional e textual - pretende uma literatura neutra, que se ajusta a toda expressão humana.

O que teríamos, portanto, é uma voz lírica, do eu lírico, que fala aquilo que está em todos os seres humanos, e não particularizado com a experiência pessoal de um sujeito - do poeta/poetisa. Percebe-se que essa posição coaduna com um dos mais tradicionais críticos de literatura de língua portuguesa, Afrânio Coutinho:
Através das obras literárias, tomamos contato com a vida, nas suas verdades eternas, comuns a todos os homens e lugares, porque são as verdades da mesma condição humana. Ela tem existência própria, é ela e nada mais, e seu campo de ação e seus meios são as palavras e os ritmos usados por si mesmos e não como veículos de valores extraliterários. (COUTINHO, 1976, p. 10)

Se dedicarmos maior atenção ao comentário de Coutinho acerca das obras literárias, encontraremos uma afirmação em parte descompromissada com as causas sociais no sentido de que essa "condição humana" é apresentada pelo autor como independente de intersecções de classe, gênero ou raça (SAFFIOTI, 2015). Ou seja, enxergar uma "condição humana" que, nas palavras do teórico, é universal e, portanto, neutra, apaga toda e qualquer diferença entre as pessoas e estabelece a noção de que o homem (branco, cisgênero, adulto, europeu, detentor dos meios de produção) é a figura única e universal.

Embora seja corrente o pensamento de que o sentido de universal se relacione aos sentimentos e emoções que seriam comuns a todos os seres humanos, como o amor, a dor, o luto, a saudade, a raiva, dentre outros, percebe-se que o ponto de vista daquele que enuncia essas emoções - o eu lírico - é específico e não universalizante como quer a crítica. Em oposição a essa falácia da universalidade, concordamos com a afirmação de Dalcastagnè (2017), para quem a valorização de um universal "nega validade às experiências humanas concretas e plurais de mulheres e homens” (DALCASTAGNÈ, 2017, n.p.) e desconsidera, sobremaneira, as possibilidades de subjetivação dos sujeitos, fazendo apenas "reforçar o uso da literatura como ferramenta de exclusão e de reafirmação das hierarquias sociais" (DALCASTAGNÈ, 2017, n.p).

Em resposta a tal contexto, o conceito de eu lírica foi inicialmente proposto em nossas pesquisas, em Souza (2015), Souza; Bertges; Pereira (2016), em Souza e Pereira (2018) e em Poubel e Pereira (2020), em estudos sobre a poesia de Maria Teresa Horta, e na sequência da pesquisa, expandido em publicações (POUBEL, 2020; POUBEL; PEREIRA, 2021), para discutir a poesia de outras autoras, 
como Mel Duarte e Joy Ladin. No conjunto desses estudos e no presente artigo, tal conceito define uma voz lírica feminina que emana do texto poético; ou seja, uma instância textual feminina que nega o masculino como voz universal da linguagem (num suposto "eu lírico" flexionado no masculino), compreendendo que não pode haver uma voz homogênea na poesia, pois não existe homogeneidade nos seres humanos, nas suas identidades ou nas suas expressões literárias. Sob tal perspectiva, propomos que a eu lírica venha a ser um expediente da crítica literária que vise à evidência de um corpo textual feminino dentro da produção lírica.

Estabelecer a universalização de uma subjetividade, ainda que esta fale sobre os dramas humanos, seja ela real ou ficcional, além de proceder ao apagamento das diferenças, também direciona as políticas para a manutenção da hierarquia de poder praticada em nossa sociedade ocidental. Dentro dessa hierarquia, as mulheres cis e transgêneras - em suas atividades "concretas aplicadas", nas suas produções subjetivas ou ainda em suas produções teóricas - são apagadas nos planos do discurso e da vivência. Por essa razão, não se pode deixar de levar em consideração a "responsabilidade institucional do crítico" (SPIVAK, 2010, p. 45), que produz esse conhecimento de um ponto de vista particular e próprio dentro da cadeia de manutenção de um sistema de poder estabelecido pelo patriarcado.

Assim, denuncia-se aqui a posição dos críticos de teoria literária que tentam universalizar o sujeito através da locução gramaticalmente masculina "eu lírico", bem como o mecanismo fascista da língua portuguesa que postula o substantivo homem enquanto representante da humanidade, usando-se de mecanismos estruturais da língua para a manutenção da hierarquia patriarcal.

Nesse sentido, percebe-se a necessidade de estabelecer discussões sobre os procedimentos e ferramentas de análise literária para poder abranger de modo mais integral todas as vozes que foram silenciadas em nome desse "homem universal", tradicionalmente presumido como identidade cisgênera e heterossexual, e eclipsando outras formas de estar no mundo e fazer gênero. Rita Terezinha Schmidt (1997) entende que não há conhecimento desinteressado e que é necessário realizar um corte ao que está postulado pelo cânone a fim de inaugurar novas possibilidades de entender a arte:

É pelo exercício do pensamento crítico que podemos realizar o corte diferencial em relação ao que aí está, pois permite o resgate das nossas energias de rebeldia e resistência não só à violência do mundo empírico, mas à violência simbólica dos códigos linguísticos, teóricos e ideológicos que o constituem e que induzem ao obscurecimento da nossa capacidade de distinguir o autêntico do inautêntico, o valor do desvalor. (...) O interesse é constitutivo do conhecimento. Isso porque os interesses dos que produzem conhecimento - os indivíduos, as comunidades científicas, os pensadores da cultura - determinam a forma do conhecimento. Poderíamos então dizer que não há conhecimento desinteressado. (Schmidt, 1997, pp.142-143)

A autora propõe uma reflexão sobre os modos de violência que a produção do conhecimento pode ensejar se entendermos que ela não é politicamente neutra e desinteressada. A produção de conhecimento está a favor de uma causa e é preciso identificá-la, seja para juntar-se a ela, seja para refutá-la e subvertê-la.

A partir dessas considerações, cumpre destacar que a eu lírica também não se pretende uma voz universalmente feminina, posto que a "mulher" enquanto signo da femininidade é múltiplo e não-uniforme, encontrando-se dentro de um continuum feminino (POUBEL, 2020) que prevê a 
realização de performances femininas dentro do continuum lésbico (RICH, 2010), isto é, nas relações de identificação entre mulheres e por mulheres.

A vivência no continuum lésbico se faz possível por compreender que as possibilidades de existência dos diversos modos de feminino se encontram dentro de um continuum feminino, no qual toda e qualquer expressão de femininidade é possível para as mulheres. Nesse sentido, mulher não é uma identidade definida, mas sim ações performáticas que vão sendo repetidas e refeitas ao longo da vida. Logo, não se é mulher, mas se performa mulher. $O$ fato de se performar mulher aponta para a noção de que não existe uma única performance fixa, mas que estas vão se construindo e desconstruindo no continuum feminino.

Assim, quando procedemos à tentativa de desconstrução dos modos de ler a poesia com o conceito de eu lírica, colocamos em xeque não apenas o masculino enquanto ocupante de uma posição hierárquica nas relações de poder, mas também tentamos apreender de que maneiras o feminino foi aprisionado dentro de uma lógica que é do centro e não pode se apresentar dentro de uma pluralidade de significantes. Desse modo, pautar-se numa essencialidade do feminino e não o compreender enquanto um continuum seria manter-se dentro da lógica falogocêntrica. Por isso, ao longo deste trabalho, o uso de feminino será feito na concepção pluralista de femininos, a qual abriga não apenas um modelo hegemônico de femininidade, mas toda a camada performativa (BUTLER, 2016) de construções do ser mulher na linguagem e nas interseccionalidades com outras dimensões das identidades humanas.

Então, se não há uma mulher essencial, pode-se dizer que as mulheres e suas definições são construídas através das relações culturais, sociais e de poder que atravessam os sistemas semióticos que usamos para compreender e definir o mundo, as relações e as posições sociais. Dessa forma, as intersecções que cortam esses significados fazem o nome mulher ser fluido e relativo, pois as referências a um sistema biológico para a definição da diferença sexual não passam de uma ferramenta do sistema patriarcal para justificar o injustificável: a dominação e subordinação das mulheres pelos homens. Mas essa definição também não satisfaz a necessidade de instauração de uma eu lírica. Saffioti (2003) discorre sobre a construção social dos gêneros da seguinte maneira:

O conceito humanista de gênero enquanto atributo de uma pessoa não serve como ponto de partida para uma concepção relacional, na qual tanto a pessoa quanto o gênero são frutos do contexto histórico que os constrói.

Conceber o gênero como uma relação entre sujeitos historicamente situados é fundamental para demarcar o campo de batalha e identificar o adversário. Nestas circunstâncias, o inimigo da mulher não é o homem nem enquanto indivíduo, nem como categoria social, embora seja personificado por ele. $\mathrm{O}$ alvo a atacar passa a ser, numa concepção relacional, o padrão dominante de relação de gênero. Diferentemente do que se pensa com frequência, o gênero não regula somente as relações entre homens e mulheres, mas normatiza também relações homem-homem e relações mulher-mulher. (SAFFIOTI, 2003, p. 55-56)

Se, como afirma a autora, uma posição idealista não permite a compreensão de que os gêneros são histórica e socialmente concebidos e padronizados, pontuamos que também não basta apenas compreender os mecanismos de regulação social realizados pelas instituições de poder tanto para a possibilidade da eu lírica na poesia, quanto para a modificação das relações entre pessoas e entre os gêneros - seja numa relação intergêneros ou intragêneros. O que buscamos nesse percurso, portanto, é encontrar maneiras de minar as definições fixas de gênero, abrindo a possibilidade de compreensão 
de que tanto o gênero feminino quanto o masculino podem ser entendidos enquanto pluralidades que ensejam em suas definições um continuum de performances.

Nesse sentido, Judith Butler (2016), em seu livro Problemas de Gênero - feminismo e subversão da identidade, propõe que, ao nos depararmos com as definições de gênero, devemos problematizá-las, ao invés de apenas refletir sobre elas. Problematizar seria a possibilidade de não apenas compreender historicamente a construção dos gêneros, mas de realizar uma pergunta reflexiva quanto a como esses gêneros são ensinados e performados e quais os limites dessas performances. Só assim poderíamos, então, subvertê-las.

Ao discutir a importância da postulação de Simone de Beauvoir, de que ser mulher é um tornarse, Butler (2009) discorre acerca das profundas consequências dessa afirmação. Entre elas, destaca-se que desvincular a ideia de gênero como algo intimamente ligado ao sexo geraria a possibilidade de uma multiplicidade de gêneros, que não estão, necessariamente, ligados à dualidade feminino e masculino.

\begin{abstract}
Considerando ainda a consequência de que, se o gênero é algo que a pessoa se torna - mas nunca pode ser -, então o próprio gênero é uma espécie de devir ou atividade, e não deve ser concebido como substantivo, como coisa substantiva ou marcador cultural estático, mas antes como uma ação incessante e repetida de algum tipo. Se o gênero não está amarrado ao sexo, causal ou expressivamente, então ele é um tipo de ação que pode potencialmente proliferar além dos limites binários impostos pelo aspecto binário aparente do sexo. Na verdade, o gênero seria uma espécie de ação cultural/corporal que exige um novo vocabulário, o qual institui e faz com que proliferem particípios de vários tipos, categorias ressignificáveis e expansíveis que resistem tanto ao binário como às restrições gramaticais substantivadoras que pesam sobre o gênero. (BUTLER, 2009, p. 195, grifo nosso)
\end{abstract}

O que essa afirmação de Butler nos oferece é uma nova ferramenta para pensar para além de uma polaridade estabelecida pelo então dito masculino e feminino. Ademais, já nos dá a entender que, para que o gênero se estabeleça, é preciso uma certa repetição de ações e atividades que se querem movência, e não estaticidade, como destacamos na passagem acima citada. A abertura de um complexo significante é, portanto, tomada como ponto de partida para essa inscrição corporal que é o tornar-se.

A autora observa ainda, nesse sentido, em seu ensaio Imitation and Gender Insubordination (1990), que estamos a todo momento nos expressando dentro de um gênero através da repetição incansável e sistemática dele (BUTLER, 1990), o que aponta para o fato de que o gênero não é o que somos, mas aquilo que teatralizamos na tentativa de incorporar. Dessa forma, o gênero performa-se no corpo através da repetição.

Essa é uma virada nos estudos de gênero que acontece na teoria queer e apregoa que o gênero, ao ser performado, visa parecer ser algo inato ao corpo e se naturalizar na sociedade enquanto uma marca indelével das relações de poder dentro dela. Contudo, é exatamente através da necessidade de ser eternamente feito e refeito numa performance que o gênero mostra a sua verdadeira forma: "[...] gênero é um tipo de imitação para a qual não existe um original” (BUTLER, 1990, p. 313, tradução nossa).

Tais contribuições dos estudos feministas e queer, na perspectiva de que o gênero é uma performance, dialogam diretamente com a obra de Joy Ladin, autora cuja poesia analisamos a seguir. Para tal, adotamos as perspectivas da eu lírica e da transpoética, termo cunhado pela escritora (LADIN apud POUBEL; PEREIRA, 2021, p. 736) para designar formas de "criar língua que signifiquem e 
expressem selves que não se enquadrem em categorias reconhecidas”, privilegiando o tornar-se em detrimento do ser.

Tal perspectiva, em consonância com a ideia de eu lírica como performances poéticas num continuum feminino, se revela tanto na produção teórica quanto na poesia da escritora, constituindo uma das linhas de força pelas quais podemos ler sua obra. Nesta, uma das questões que se sobressai a partir da transpoética é o variado escopo semântico de palavras indicativas de identidades de gênero, como girl, em poemas como "Girl in a Bottle" e no artigo "Girl in a Bottle: An autobiographical Excursion into the Poetics of Transsexuality" (LADIN, 2015), ou woman, em palestras como "Ain't I a Woman" (LADIN, 2016). Questionando as fronteiras que a sociedade impõe ao uso de termos como esses, a autora afirma em sua poesia outras formas de fazer e ser ora girl, ora woman, nas performances de suas eu líricas.

Como exemplo de realização da transpoética, o poema a seguir, "It like me”, de Joy Ladin, questiona os binarismos de gênero da linguagem ao assumir que o pronome it, que assumiria uma identidade neutra na língua inglesa, contém, por meio de uma série de comparações, uma conotação feminina por sua identificação com a natureza - comumente associada ao feminino.

\author{
It like me \\ Earth is an it \\ An it and a she \\ A she and an it \\ It like me \\ Earth has no womb no monthly bleeds \\ Has never kept house for patriarchy \\ Isn't really much of a she \\ She is an it - an it like me \\ Fellow it, let's make a we \\ A publicly secret society \\ Of its whose she-ness \\ Is hard to see \\ Is basalt magma \\ And molten sea \\ Its who are worlds \\ Its like me \\ (LADIN, 2017, p. 11)
}

Se o poema apresenta uma tensão com o pronome it, também o faz em relação à figura quase mitológica da natureza enquanto feminina, uma vez que, assim como a eu lírica, a natureza não possui os "caracteres" ditos femininos pela sociedade. Logo, o poema constrói-se através da comparação entre esses dois its na formação de uma nova possibilidade de feminino - que não é reconhecida socialmente dentro do feminino enquanto o outro do masculino. Portanto, não é a não-homem, e na autoidentificação encontra ancoragem para se afirmar nestes continua lésbico e feminino. 
Nesse sentido, compreende-se que o poema pode ser lido na perspectiva do que Joy Ladin compreende como transpoética:

\begin{abstract}
uma voz buscando expressar identidades que não se conformam a categorias reconhecidas socialmente, isto é, uma poética centrada na palavra. Neste sentido, podemos entender a Transpoética como uma poética que não se encaixa no mundo binário da cisnormatividade. Não é só uma poética das pessoas transgêneras, mas fala através de vozes não conformativas que compreendem diferentes performances do ser. (LADIN apud POUBEL; PEREIRA, 2021, p. 727, tradução nossa)
\end{abstract}

Numa voz transpoética, a eu lírica não apenas não se encaixa numa cisnormatividade como também foge de definições estáticas centradas no substantivo. O pronome it é também um pronome dêitico, que aponta para o aqui e agora: $\mathrm{o}$ it está sempre em relação a algo, portanto prevê em si mesmo a possibilidade de transformar-se. O jogo da comparação é realizado no poema através de repetições, inversões sintáticas e paralelismos, e através destas figuras de linguagem também observamos uma busca por semelhança, uma tentativa de identificação.

Na primeira estrofe, "Earth is an it/An it and an she/A she and an it/It like me", a repetição leva à analogia de que, se a terra é um ela e um isto (lembrando que o pronome it em inglês corresponde em português ao pronome isto e pode ser utilizado para designar seres inanimados, sujeito para um verbo que não necessita de sujeito, e uma criança muito pequena, especialmente aquelas que ainda não tiveram a designação de seu gênero em virtude de seu sexo), a eu lírica que é um isto também é um ela. Ou seja, autoidentifica-se enquanto instância enunciativa feminina.

Para a continuidade das analogias, as características femininas dadas através da biologia do sexo feminino são utilizadas para apontar que um ela não corresponde, necessariamente, ao que se convencionou chamar de feminino: a terra, este isto, não tem útero e não sangra mensalmente, da mesma forma como a eu lírica não realiza este feminino. Curioso notar neste ponto a ironia presente no fato de que a Terra - metonímia da mãe natureza - não possui um útero, ainda que no imaginário social ela receba essa alcunha de feminilidade ligada à maternidade por sua capacidade de gerar, mesmo que seja uma criação não uterina. Logo, nem na representação simbólica da feminilidade há a necessidade de designação dada através de um corpo biológico. O verso que segue esta afirmação, "Has never kept house for patriarchy”, enuncia outra característica que difere do feminino culturalmente aceito, um feminino subjugado pelo patriarcado. Não se enquadrar no padrão de gênero binário pode corresponder a também subverter a hierarquia existente entre os gêneros. Este feminino em jogo na performance da eu lírica aponta seu afastamento da mulher "universal": "Isn't really much of a she/She is an it - an it like $m e$ ".

Podemos afirmar também que a estrutura de repetição, neste caso, cria um eco sonoro e visual, pois, se anteriormente o pronome it buscou se assemelhar à terra, nesta estrofe o encadeamento de ideias, sua progressão, nos leva ao que podemos chamar de esvaziamento do pronome ela por descaracterizá-lo em relação ao binário ela-mulher universal. Nos versos já apontados, "has no womb, no monthly bleeds, has never kept", observam-se dois tipos de repetição que dão a sensação de semelhança: uma pela manutenção da negativa, seja através do no ou do never que fortalece os laços entre as duas entidades; e a outra a partir da repetição do verbo has, que está implícito em "(has) no monthly bleeds", causando essa continuidade semântica das negativas, que segue, ainda, nas repetições do terceiro verso dessa mesma estrofe. Logo, podemos afirmar que a busca por uma identificação com o feminino é 
divergente da busca pelos padrões patriarcais de feminilidade, por isto este it "isn't really, isn't much of a she"; há o nascimento de um novo feminino que aqui constitui uma femininidade (em contraposição $\grave{a}$ feminilidade enquanto adjetivação do feminino nos conceitos patriarcais e cisgêneros).

A partir desse jogo de identificação, seja através do reforço da comparação ou da negação, podemos compreender que o feminino se encontra num continuum que abarca outras possibilidades de existências femininas e, para combater a subjugação, há, na voz lírica, um clamor para uma união dessas novas performances de elas que não são vistas em sua femininidade, mas que buscam visibilidade, daí a contradição presente no verso "A publicly secret society”. O verso seguinte, "Of its whose she-ness is hard to see", confirma essa relação, criando também um jogo de linguagem com its e she-ness, uma vez que o pronome it não faz plural em its; ou seja, há novamente uma quebra da relação significado-significante de forma a personificar essa sociedade. Ainda, a palavra she-ness, grafada com o uso do hífen, ressalta a formação morfológica da palavra. Se o sufixo ness é utilizado para transformar um adjetivo ou um particípio em substantivo, sua ligação a um pronome novamente esvazia o pronome, fazendo com que ele contenha em si diferentes possibilidades de significação. $O$ significante se mantém na cadeia do vazio. Encontramos, dessa maneira, o abismo proposto pela linguagem que não se deixa aprisionar no significado, e a abertura para formas transpoéticas de performance de identidades de gênero no poema.

O jogo de formação de palavras através do esvaziamento proposto pelo uso do pronome e pelas novas relações estabelecidas no texto ganha força na última estrofe: "Is basalt magma/ And molten sea", pois sabe-se que na mitologia bíblica do Antigo Testamento o mar basáltico representa o dilúvio, evento divino que através da inundação modificou a vida na Terra e foi responsável pela nova forma geológica do planeta. Já o mar de cobre ou mar fundido - molten sea - é o local no qual, ainda na mitologia bíblica (Êx 30: 17-21; 1Rs 7: 23, 40,44), os sacerdotes se banhavam para se purificar. E, segundo João, ao analisar o Apocalipse, o mar fundido recebe o nome de mar vítreo e é o local no qual Deus purifica através da palavra aqueles que se convertem. Por analogia, podemos dizer que a femininidade desse coletivo de its não vem, necessariamente, de um corpo, mas sim de uma transformação que passa tanto pelo corpo quanto pelo divino. Mas que, acima de tudo, só ocorre através do esvaziamento da linguagem para a sua multiplicação de significados.

O verso final: "It who are words/Its like me” fecha o poema com a repetição do título, transformando o it nessa comunidade de its. A “purificação” pela palavra é também a possibilidade polifônica da linguagem: através dela podemos estabelecer novas relações que pretendem fugir do binarismo de gênero imposto pelo patriarcado. A femininidade ganha espaço na possibilidade da autoidentificação que transborda os ditames patriarcais.

E se estamos falando de purificação pela palavra, podemos refletir sobre o papel que a literatura possui dentro da linguagem. Para Barthes (2007), a literatura, ou melhor, o texto poético é aquele com a potência de subverter a rigidez e a imposição da língua. $O$ texto, em seu vir a ser, na sua construção eterna entre a mão que escreve e a voz que declama, nunca está terminado, pois existe enquanto potência. Logo, essa palavra sagrada, purificadora, faz parte de tudo que não pode ser denominado, que não recebe um nome, um significado fixo. Daí a beleza da utilização do termo it e a subversão da eu lírica ao torná-lo plural, its. Se vivemos em uma sociedade que cristaliza ao dar o nome, através da voz lírica que emana do poema encontramos a subversão de todo um sistema, marcado no poema também através da subversão da norma gramatical. 
Para refletirmos um pouco mais sobre a potência subversiva do poema, texto, linguagem e performances transpoéticas de eu lírica, apresentaremos uma análise do próximo texto, “The Poem and $M e$ ”. Já de saída encontramos no título uma relação que nos leva a indagar: O que o poema e a eu lírica têm em comum? Ou melhor: como essas duas entidades textuais se relacionam e se constroem dentro do texto poético? Ressalta-se, neste momento, que o fluxo de significantes que se constrói através da estrutura poemática não apenas dá possibilidades de interpretações para o texto, mas também redobra a noção de que a eu lírica é construção, movência - vive na lei do verbo.

\section{The Poem and Me}

The poem walks from me toward meaning

that may or may not be there

By the time it returns

I am someone else

though to the poem

which walks at relativistic speeds

no time at all has passed

That's why the poem looks so puzzled

when it finds I've forgotten

how we are related

The poem and I disappoint one another

Rather than mother and child body and soul

we turned out to be one-night stands

The Earth has moved my head throbbed

but when the poem returns many years later

it seems like nothing happened

I remember now how the poem began

I was looking out the window

It was winter summer there was a Bird

or a memory of a Bird

a screech I suddenly heard a song

a pain that felt like explanation

I lay on the floor of the world

pieces of a toy

the poem began to play with.

(LADIN, 2017, p. 8) 
Na leitura do poema, percebe-se que essa relação estabelecida entre esses dois eus (o do poema e o da eu lírica) se dá no movimento de ida e de retorno, num deslocamento contínuo, algo que corre em um tempo que não é cronológico e em um espaço que está para além do físico, pois transborda o seu suporte. Observa-se que o poema não é objeto, não pode ser trancafiado; ele funciona como texto, e como texto recebe certa autonomia na sua personificação.

Logo nos primeiros versos lemos "The poem walks from me toward meaning/ that may or not may be there”. Nota-se que o poema adquire a ação de mover-se, ele se afasta da eu lírica em direção ao significado. Há uma vida própria que é do texto e que não faz parte da vida da eu lírica. A princípio poderíamos crer que o poema estaria contido na eu lírica, seria parte dela, tendo apenas uma possibilidade de significar dentro dessa relação. Contudo, exatamente porque o poema pode se constituir enquanto texto e não obra (Barthes, 2004), o significado não é algo estável, não é algo que possa, em última instância, existir. Ele "caminha" para o significado, mas, como texto, este significado fixo não é possível, por isto a marca da possibilidade - "may or not". A cadeia de significantes não deixa que ele se estagne em algum lugar, de modo a estar sempre em adiamento.

A próxima estrofe do poema, em consonância com a oitava, vai nos oferecer a sensação de eterno movimento como citado acima, pois o poema parte, mas sempre retorna. Retorna para quê, exatamente? Não mais para a mesma eu lírica e não mais para o mesmo espaço, porque estes já não existem - em suas qualidades de texto, ambos já percorreram outras direções dentro da linguagem: "By the time it returns/I am someone else" (...) "But when the poem returns many years later/ it seems like nothing happened”. Nesses dois versos, pode-se observar essa dualidade do ir e vir, que ora encontra um traço em comum, mas que já está na memória (como podemos ler nos versos que se seguem no poema), ora não é mais cognoscível.

A ideia de um tempo que passa é central no poema e é perceptível tanto pela modulação de tempo verbal - que ora está no presente, ora no passado simples, num jogo que ocorre ao longo de todo o poema -, quanto pelas palavras que nos remetem ao tempo, tais como: time, returns, walks, speeds, one-night stands, moved (pelo movimento da terra), years later, remember, memory, winter, summer. Quando retornamos essas palavras para seus devidos versos, percebemos que elas estabelecem uma relação entre a eu lírica e o poema, e que o encontro entre essas duas entidades, nas performances que ambos ensejam como linguagem, é causa de desconforto, de estranhamento, como se nota pelas palavras puzzled e throbbed.

Entre todos os versos que nos revelam o tempo, os que parecem mais expressivo são "It was winter summer there was a bird/ or a memory of a bird”. A ligação entre inverno e verão nos dá a sensação de uma rotação de 180 graus, de um tempo que passa. Se de verão voltarmos para o inverno, teremos, portanto, uma rotação completa de um ano em nosso tempo, mas que é dispensável para a eu lírica e para o poema, uma vez que o tempo cronológico desaparece na linguagem. É interessante que as sentenças que se seguem nos trazem outra dualidade temporal entre a presença de um pássaro ou sua memória, o que nos remete novamente a esse tempo que caminha em diversas direções. Essa posição pode ser confirmada pelas estrofes quatro e cinco, nas quais podemos ver que o tempo de fato não passa, embora pareça ser rápido quando se vê o poema passar. Logo, temos uma relação que é estabelecida pelo tempo, mas que por esse também se desmancha, tornando-se difusa. 
A relação entre poema e eu lírica vai se modificando através dos versos, como performances transpoéticas reinventadas no ato da enunciação, mas parece que há um momento de esclarecimento que gradualmente vai sendo apresentado pela voz lírica. Na quinta estrofe, o poema toma consciência do esquecimento da eu lírica sobre ele, e algo que parecia tão coerentemente em uma unidade é desfeito. As comparações que a eu lírica utiliza nesse momento para sustentar essa imagem talvez sejam as mais fortes dentro do que nós - leitoras - tenhamos a partir da nossa cultura ocidental judaico-cristã: a relação da mãe com a criança e a do corpo com a alma. A utilização da conjunção rather than nos diz dessa relação poema-eu lírica que aparentemente é mais intensa e mais embrenhada do que as outras duas, sendo que a relação mãe-criança e corpo-alma nos dizem de aspectos fundantes da nossa cultura. Portanto, se a relação entre poema e eu lírica não é nada mais que um momento "one night-stands" (nos fazendo, inclusive, remeter a uma relação amorosa), as outras são ainda mais frágeis. Neste ponto perguntamos: o que essa única noite representa em termos de linguagem? Talvez indique que a eu lírica só pode ter um poema, naquele aqui e agora de seu nascimento, no momento em que foi obra. Mas, a partir do instante que deixa de ser obra e se transforma em texto, a eu lírica e o poema jamais se encontrarão novamente, pois serão outros, a partir de outras miradas, de outras perspectivas e jogos que a própria leitora lhes atribui.

Quando chegamos à nona estrofe, a eu lírica se coloca com mais força nessa relação a partir da memória, que a ajuda a reconectar a sua própria história com o poema. A lembrança vai sendo anunciada gradativamente; ela recorda o início, um local, o tempo que mais uma vez é misturado, um pássaro e, de repente, um som. Um som que não é som de lira, mas um berro, um grito; do berro para a música e então a dor como momento de lucidez. A eu lírica já não tem mais força para se manter uma e se desfaz, percebe-se como apenas peças de um jogo, jogado pelo poema. A eu lírica é a fantasia do próprio poema, e por este não poder se manter fechado, visto que é fruto da linguagem poética, a eu lírica permanecerá em processo de vir a ser, sempre nos olhos de quem a lê.

O jogo de performance está aí apresentado, quando a eu lírica se faz no aqui e agora do texto. Ela própria enquanto texto se abre a novas possibilidades de ser, de transformar-se. Assim, na impossibilidade de sedimentação, não se faz escultura, permanece enquanto possibilidade e performance diante de nossos olhos e sentidos.

Refletindo acerca dessa movência que se constitui enquanto eu lírica e poema, apresentamos a seguir a leitura do poema "Not Unlike" para observarmos a relação entre a linguagem e a constituição de uma identidade transpoética. 


\author{
Not Unlike \\ I am not not, I am not un-, I am not unlike \\ a forgotten word \\ balanced on the tip of a tongue, \\ I do not dis-identify \\ with sparrows, snow patches, unpopped corn or unpresiding presidents, \\ I am not unsympathetic \\ to the melting of icecaps, \\ I neither confirm nor deny \\ the moral implications \\ of the disingenuous empiricism \\ from which I cannot detach myself \\ as I attempt to disentangle \\ filial assumptions from the flesh \\ of the son who turns away when I wave, \\ nor can I readily distinguish \\ the privileges of walking the earth, \\ earning, owing, giving and forgiving, \\ from the privilege of standing at the intersection \\ of subjectivity and subjection, \\ smiling at babies, singing psalms, confessing my racism, \\ telling a story that is not unlike my life \\ to a sky as distant as the ear \\ of the man my young son loved \\ when I was not unlike his father. \\ (LADIN, 2017, p.45)
}

Não partimos, aqui, da suposição que o texto em si apresente uma identidade feminina, mas sim da decisão enquanto leitoras de que há uma autoidentificação feminina na produção do texto. Como discutido em Poubel (2020), a eu lírica se constitui enquanto texto a partir de uma autoidentificação com o feminino, logo, quando o olhar transpoético se encontra com esta escolha de leitura crítica, podemos inferir no texto esta identidade que está no movimento de tornar-se, que não é diferente, mas que também não se identifica. A constituição da eu lírica acontece na sua identificação com um pai que um dia se foi e com a mulher que se é ao constituir-se em voz poética, num trânsito entre diferentes performances de gênero e formas de estar no mundo ao longo da vida. Tal fluidez também pode ser observada na sintaxe do poema e nas imagens que vão gradativamente passando de umas às outras em enumerações como "with sparrows, snow patches, unpopped corn or unpresiding presidents" ou "smiling at 
babies, singing psalms, confessing my racism". Falando de sua própria obra, Joy Ladin (2021) também se refere à sintaxe fluida de alguns de seus poemas e de outros escritores, como Emily Dickinson, como marcas transpoéticas.

Em "Not Unlike", o uso de palavras e prefixos que nos entregam a negação, ou uma contraposição apontando uma diferença, ou mesmo a falta dela - no caso de unlike - pode nos encaminhar para a suposição de que a formação de uma subjetividade está relacionada à comparação com o que já existe no mundo. No poema, "I am not", "not un-", "not unlike”, "I do not dis-identify", "unpopped”, "unpresiding”, "unsympathetic”, "disingenuous", "disentangle” são palavras e expressões que parecem sobreviver na interseção entre ser e não ser, no transformar-se. Há, na composição do poema, o próprio processo de tornar-se alguém novo que ainda está repleto da subjetividade de quem se foi, porque a vida, em si, não consegue ser desprendida.

O próprio poema é a chave principal de leitura, dado que se apresenta como o corpo textual em que a eu lírica se constitui como voz, identidade e existência, "telling a story that is not unlike my life", para ressignificar a si mesma e sua relação com outros sujeitos, em especial o filho a que alude por meio dos versos "filial assumptions from the flesh/ of the son who turns away when I wave" e "of the man my young son loved/ when I was not unlike his father". A comunicação com o filho, possivelmente interrompida pela incompreensão em relação às mudanças nas performances de gênero da eu lírica, é sugerida pelas palavras que não se dizem, “(...) a forgotten word/balanced in the tip of the tongue”, e que só se enunciam no poema como forma de fazer a si mesma como linguagem. Nessa enunciação, não se observa, porém, a simples substituição de father por mother, que limitaria a um binômio a identidade e a expressão de gênero da eu lírica em suas relações familiares. Em lugar da simples negação ou substituição de uma identidade parental, temos aqui uma abertura para outras possibilidades, marcada por termos como disentangle e detach. Pode-se, de maneira arbitrária refletir, que assim como os constructos binários de feminino e masculino são transformados por uma não adequação pessoal que embora implique uma questão social ainda podem ser enxergados da perspectiva da individualidade, o binômio pai-mãe enquanto marca cultural é mais enraizado na relação social por apresentar não apenas uma vivência pessoal, mas por apontar para uma cadeia de relação já que se pode ser pai/mãe, mas um filho/filha também designam uma mãe/pai. Assim, das relações cridas como mais viscerais na sociedade, uma mudança no status familiar pode não acontecer na mesma medida em que ocorre uma mudança de gênero. Daí a relação ainda mais intensa e complicada entre um ser e não ser apresentado pela eu lírica.

Trata-se, nesse processo, de uma eu lírica que vai se (re)constituindo ao mesmo tempo a partir de afirmações que se dão como negações, não permitindo que se feche o sentido ou sua identidade em fórmulas simples ou binárias, dado que permanece como potência "from the privilege of standing at the intersection/ of subjectivity and subjection". Reforçando tal ideia, ao dizer "I neither confirm nor deny", temos uma performance em que o eu se dá de modo fluido e transpoético na relação consigo mesma, seu passado e o mundo social ao redor, nem confirmando nem negando os processos de (auto) identificação, no que retoma o procedimento da comparação presente no título deste poema e nos demais analisados neste artigo ("It Like Me" e "The Poem and Me").

À guisa de conclusão, destacamos que, nas discussões ora apresentadas, procuramos colocar em pauta a necessidade de instauração da eu lírica como uma voz feminina gendrada na poesia, discutindo como as teorias feministas e queer contribuem para o que chamamos de continuum feminino dentro 
de performances dos femininos. É, afinal, dentro desse continuum que Joy Ladin realiza a construção de sua obra poética e que suas eu líricas performam modos de estar no mundo e na linguagem que nos fazem pensar sobre a potência estética, ética e política de uma escrita que a autora afirma como transpoética, transcendendo binarismos de gênero na linguagem e na vida em sociedade.

Problematizando o escopo do signo mulher, bem como as formas de construir-se como tal por meio da palavra, os poemas de Ladin que analisamos ampliam as possibilidades de enunciar mulher e fazem com que cada eu lírica seja singular na sua experiência da enunciação, a partir de processos de identificação e identidade. Na impossibilidade de existir um ser universal que possa falar por cada individualidade enunciativa, as eu líricas de Joy Ladin performam suas identidades de maneira única e se transformam a cada nascimento de leitora e a cada leitura de seus poemas. Em todos eles, ressoa a pergunta que dá título à sua fala no TED Talk de 2016 e nos faz pensar a voz transpoética das eu líricas: "Ain’t I a Woman?".

\section{REFERÊNCIAS}

BARTHES, Roland. "A morte do autor”. In: BARTHES, Roland. O Rumor da Língua. São Paulo: Martins Fontes, 2004.

BARTHES, Roland. Aula. São Paulo: Cultrix, 2007.

BÍBLIA. Português. A Bíblia Sagrada: Antigo e Novo Testamento. Tradução de João Ferreira de Almeida. Edição revisada e atualizada no Brasil. Brasília: Sociedade Bíblia do Brasil, 1969.

BUTLER, J. Frames of war: when is life grievable? New York: Verso, 2009.

BUTLER, Judith. “Imitation and Gender Insubordination”. In. ABELOVE, Henry; BARALE, Michèle Aina; HALPERIN, David M. The Lesbian and Gay Studies Reader. New York, London: Routledge, 1990, p. 307-320.

BUTLER, Judith. Problemas de gênero: feminismo e subversão da identidade. Tradução de Renato Aguiar. 12. ed. Rio de Janeiro: Civilização Brasileira, 2016.

COUTINHO, Afrânio. Notas de teoria literária. Rio de Janeiro: Civilização Brasileira, 1976.

DALCASTAGNÈ, Regina. "Sobre uma crítica que ignora o real”. PERNAMBUCO: Suplemento Cultural do Diário Oficial do Estado. 2017. Disponível em: <http://www.suplementopernambuco.com.br/ edi\%C3\%A7\%C3\%B5es-anteriores/72-resenha/1825-literatura-mutante,-cr\%C3\%ADtica-im\%C3\%B3vel. html>. Acesso em 23 ago. 2017.

HAMBURGER, Käte. A lógica da criação literária. São Paulo: Perspectiva, 1975.

KRISTEVA, Julia. Revolution in Poetic Language. New York: Columbia University Press, 1984.

LADIN, Joy. “It Like Me”. Vetch: a magazine of trans poetry and poetics. N. 1, Autumn, 2015, p. 59.

LADIN, Joy. The Future is Trying to Tell Us Something - New and Selected poems. Rhinebeck: The Sheep Meadow Press, 2017.

LADIN, Joy. “Ain't I a Woman?”| TEDxBeaconStreet. YouTube. 2016. Disponível em <https://www.youtube. com/watch?v=g0K2YvvQyEw>. Acesso em 03 abr. 2021.

LADIN, Joy. "Entrevista”. In: POUBEL, Natália Salomé; PEREIRA, Vinícius Carvalho. Language, Body and Trans Poetics: An Interview with Joy Ladin. Ilha do Desterro. v. 74, n. 1, Florianópolis, jan/abr 2021, p. 727-739. 
MOISÉS, Massaud. A criação literária. São Paulo: Cultrix, 2012.

PAZ, Octavio. O arco e a lira. Tradução de Olga Savary. Rio de Janeiro: Nova Fronteira, 1982.

POUBEL, Natália Salomé. Performatividade de gênero: a eu lírica na poesia escrita por mulheres. Tese (Doutorado). Universidade Federal de Mato Grosso, Instituto de Linguagens, Programa de Pós-graduação em Estudos de Linguagem. Cuiabá, 2020.

POUBEL, Natália Salomé; PEREIRA, Vinícius Carvalho. "Quantas Marias há na lírica de Maria Teresa Horta: uma questão de performance”. Scripta Uniandrade, v. 18, n. 1.2020, p. 181-195.

POUBEL, Natália Salomé; PEREIRA, Vinícius Carvalho. "Language, Body and Trans Poetics: An Interview with Joy Ladin”. Ilha do Desterro. v. 74, n. 1, Florianópolis, jan/abr 2021, p. 727-739.

RICH, Adrienne. "Heterossexualidade compulsória e existência lésbica”. Revista Bagoas, n. 05, 2010, p. 17 - 44.

SAFFIOTI, Heleieth. "Conceituando o gênero". Gênero e educação - caderno de apoio para a educadora e o educador. Secretaria Municipal de Educação. Coordenadoria especial da mulher. Prefeitura de São Paulo, junho, 2003, p. 53-60.

SAFFIOTI, Heleieth. Gênero, patriarcado, violência. 2. ed. São Paulo: Expressão Popular: Fundação Perseu Abramo, 2015.

SCHMIDT, Rita Terezinha. "O papel do profissional de Letras: compromisso com a realidade". Cadernos do Instituto de Letras, n.18, Porto Alegre: UFRGS, dez. 1997.

SOUZA, Natália Salomé. A escrita feminina na lírica de Maria Teresa Horta. Dissertação (Mestrado). Universidade Federal de Mato Grosso, Instituto de Linguagens, Programa de Pós-graduação em Estudos de Linguagem. Cuiabá, 2015.

SOUZA, Natália Salomé; BERTGES, Lívia Ribeiro; PEREIRA, Vinícius Carvalho. "Maria Teresa Horta: escrita feminina na poesia de um corpo liberto”. Interdisciplinar. Ano XI, v. 26, set.-dez, 2016, p. 123-136.

SOUZA, Natália Salomé; PEREIRA, Vinícius Carvalho. "A escrita da mulher/ a escrita feminina na lírica de Maria Teresa Horta”. Revista Estudos Feministas. Florianópolis, 26(2), 2018, p. 1-14.

SPIVAK, Gayatri Chakravorty. Pode o sulbaterno falar? Trad. Sandra Regina Goulart Almeida, Marcos Pereira Feitosa, André Pereira Feitosa. Belo Horizonte: Editora UFMG, 2010.

WELLEK, René; WARREN, Austin. Teoria da Literatura. 2. ed. Lisboa: Publicações Europa-América, 1971. 